\title{
Exposing Pharmacy Students to Challenges Surrounding Care of Young Children via a Novel Role-Emerging Placement
}

\author{
Efi (Efthymia) Mantzourani ${ }^{1, *}$, Rhian Deslandes ${ }^{1}$, Laura Ellis ${ }^{1} \&$ Greg Williams ${ }^{1}$ \\ ${ }^{1}$ Cardiff School of Pharmacy and Pharmaceutical Sciences, Cardiff, Wales, UK \\ *Correspondence: Cardiff School of Pharmacy and Pharmaceutical Sciences, Cardiff, Wales, CF10 3NB, UK. Tel: \\ 44-2920-870-452. E-mail: MantzouraniE1@cardiff.ac.uk
}

Received: December 2, 2015

Accepted: January 7, 2016 Online Published: May 19, 2016

doi:10.5430/jct.v5n1p124

URL: http://dx.doi.org/10.5430/jct.v5n1p124

\begin{abstract}
Embedding opportunities for undergraduate pharmacy students to move between academic and practice environments is key to transform their perception of patient care and to facilitate learning of the skills required for the changing profession (Smith and Darracott, 2011). An approach adopted by many health care professions to prepare students for diversity with their field, is exposure to non-workplace environments in the form of role-emerging placements (REPs) (Whiteford and Wright St-Clair, 2002).

The study presented is part of an ongoing action research project; this cycle focusses on exposing students to challenges surrounding care of young children. Barriers and facilitators arising from an earlier pilot of REPs in the Cardiff School of Pharmacy were considered when designing and implementing innovative placements for entry level pharmacy undergraduates in venues where mother and toddler groups were running. Students participated in a pre-placement workshop where they explored a flexible list of questions to facilitate their interactions. Placements were supervised by members of staff, who supported students throughout their experience and during a group debrief at the end of each session. Students were called to reflect further during a post-placement workshop with the rest of their colleagues.

The full cohort of students submitted a copy of their overall reflections. Entries were analysed via thematic analysis to provide an overview. The sessions raised awareness of issues when providing pharmaceutical care to children and contributed to students' professional development. Challenges to their interactions were identified and suggestions for improvement were made. Results will inform structure and content of future REPs.
\end{abstract}

Keywords: pharmacy education; practice placements education; role-emerging placement; pharmaceutical care of children; action research

\section{Introduction}

\subsection{Pharmacy Education and Placements}

The General Pharmaceutical Society (GPhC) is the regulatory body for pharmacy in the United Kingdom, In the UK, it takes a minimum of five years to qualify as a pharmacist. This includes a successful completion of a GPhC accredited Master of Pharmacy Degree (MPharm) and one year pre-registration training in a community or hospital pharmacy (GPhC, 2015a). The GPhC sets outcomes for an MPharm degree and pre-registration training in a document containing ten standards; these include curriculum delivery and the student experience. It ensures every school of pharmacy provides the same high level of education and training (GPhC, 2010).

To help students transition from education into practice and the healthcare team, practical clinical experience through placements is required (Cohn and Crist, 1995). Development of confidence and professional identity are among reasons why placements are beneficial for students (Cooper and Raine, 2009). In addition, placements allow theoretical based knowledge to be seen in practice (Moffitt and Davison), an area which is lacking, according to student feedback to the British Pharmaceutical Society Association, BPSA (Smith and Darracott, 2011).

In the general standards, the GPhC recognizes the importance of practice placements and state that students require opportunities that provide independent learning and integrated pharmacy practice experience (GPhC, 2011). 
However, information on specifics is limited. A pharmacy student must simply undertake "practical experience" as outlined in standard 5.6 (GPhC, 2011a). The GPhC recognises the importance of cross section experience (CSE) for students to gain an understanding of the pharmacist's role in primary, secondary and tertiary care. Students are encourage to spend time in "another patient facing sector" to meet the standards of CSE during their pre-registration year (GPhC, 2011b). However there is not emphasis on CSE during the first four years.

Therefore, most universities generally arrange placements for students in traditional pharmacy environments such as a community or hospital setting (UCL School of pharmacy, 2015; Durham University, 2015).

\subsection{Challenges of Traditional Pharmacy Placements}

Pharmacy is classed as a science degree thus less funding is provided compared to a healthcare degree. This greatly limits the number of placements that can be undertaken according to a report by Medical Education England (MEE) board (Smith and Darracott, 2011). Healthcare courses such as nursing and occupational therapy, require a high proportion of placements and practical experience due to regulations set by health and care professions council (HCPC) 2009 (Health and care professions council, 2012). Funding from the NHS or the Higher Education Funding Council for England (HEFCE) is necessary for clinical teaching payments which pharmacy schools do not receive (Smith and Darracott, 2011). Additionally, pharmacy student numbers have increased in the last years, and providing traditional placements to accommodate multiple opportunities for learning is increasingly challenging (Huddleston, 1999). In practice, schools of pharmacy provide short observational placements, and one of the main challenges reported by students is limited meaningful opportunities for patient contact (Abbas et al, 2013)

The role of the pharmacist is ever evolving, from the supplier of medicines into more diverse roles (Noble et al, 2014). The report by the MEE board, reviewed pharmacist undergraduate education and pre-registration training and it identified that more effective training was required to prepare pharmacy students for what is expected of them in practice (Smith and Darracott, 2011). There were concerns that the four year degree concentrated predominantly on developing the knowledge and skills and didn't adequately develop "work-based practice". It was acknowledged that more opportunities for the student to move between academic and practice environments along with an integrated curriculum would be more beneficial for students to learn the skills required for the changing profession (Moffit and Davison; Smith and Darracott, 2011).

\subsection{Role-Emerging Placements}

An alternative approach, taken by other health care professions, to prepare students for diversity with their field, is the use of role-emerging placements (Whiteford and Wright St-Clair, 2002). Role-emerging placements (REPs), also known as non-traditional placements, have been used predominantly in occupational therapy (OT) (Overton et al, 2009). In OT, the term refers to "placements in non-statutory settings with no established occupational therapy service" (College of Occupational Therapists, 2006). For pharmacists, this could refer to introduction into different primary care settings, as outlined by the Welsh Government (National Health Service Wales, 2014), or to exposure to a range of patient groups.

Extensive research into the use of REPs in occupational therapy highlights the advantages and challenges of REPs (Overton et al., 2009). It suggests that students can explore new innovative areas of occupational health whilst also developing core skills (Cooper and Raine, 2009). Students also began to develop a professional identity which in turn made them feel confident in their role (Clarke et al, 2014). Thew et al's research in 2008 shows that students became more autonomous and independent following REPs; two key skills required by pharmacy students. REPs have also shown the potential to provide a solution for other problems faced in OT such as increased student numbers. It emerges that REPs show great potential for use in pharmacy.

\subsection{Role-Emerging Placements in Pharmacy}

There has been little research into developing practical experience or REPs in pharmacy. The first published study in 2013 in British Columbia, Canada, highlighted some potential benefits for the use of REPs in pharmacy (Kassam et al, 2013). The study, however, concentrated solely on pharmacy preceptor's and staff experiences rather than students. Gwyn et al (2015) designed a REP exploring sexual health with young people. Pharmacy students participating reported a worthwhile experience, raising their awareness of challenges related to interacting with this specific cohort of patients on such a sensitive issue, and providing them with an insight into advantages of alternative approaches to educating patients.

\subsection{A Novel Role-Emerging Placements with Young Children}

In Cardiff School of Pharmacy and Pharmaceutical Sciences an action research project was launched in 2013. The 
first cycle was completed in 2014 and focused on evaluating the introduction of a pilot REP with elderly service users (Mantzourani and Hughes, 2015). The aim of the placement was to expose students to a cohort of service users from one end of the spectrum of life: the elderly. Feedback from students was used to introduce a second cycle, focussing on exposing students to the other end of the spectrum of life: young children. The intended learning outcomes of the placement were agreed taking into account the level of studies of the students (presented in Table 1).

Group placements were organised for entry level undergraduates in venues where mother and toddler groups were running, between January and April 2015. Group organisers in venues used for REPs were prepared for the placements via face-to-face visits. Aligning the site's expectations with the students' nature and capabilities was emphasised in Rodger et al. (2009) as an important factor contributing to the success of a REP.

All students participated in a pre-placement workshop where they explored a flexible list of questions to facilitate their interactions. On-site supervision was adopted, based on reflections of a previous action research cycle concentrating on the pilot REP undertaken by students in a previous year. Placements were supervised by members of staff of the University, who supported students throughout their experience and during a group debrief at the end of each session. All placement educators were briefed by the academic placement lead, to ensure consistency in expectations and approach of supervision. Students were called to reflect further during a post-placement workshop with the rest of their colleagues. This approach was adopted as discussion in a post-placement session is acknowledged as a useful tool to enhance reflections on pharmacy observational placements (Mantzourani and Deslandes, 2015) and helps students revisit their placement and turn surface into deep learning. Other ethical issues considered were clear guidelines for confidentiality and adequate insurance (Wood, 2005).

Table 1. Intended Learning Outcomes of the Placement

On successful completion of the placement, the student should:

1. Knowledge Discuss the factors that have an impact in pharmaceutical care of children

Discuss previous experiences of parents and carers with the healthcare system, in relation to children

Discuss how and why various contexts influence decision-making of parents and carers towards seeking advice from a pharmacist

2. Skills

Develop their communication skills with members of the public

Outline the different needs of parents and carers in relation to pharmaceutical care of children

3. Attitude Accept individual differences in parents and carers and the impact in pharmaceutical care of children

Accept cultural differences in parents and carers the impact in

pharmaceutical care of children

Value the contribution of social interaction in a mother \& toddler group

Table 1 presents the specific intended learning outcomes of the role emerging placement in mother \& toddler groups. The outcomes are presented in relation to knowledge, skills and attitudes.

To the authors' knowledge this is the first time a role-emerging placement for undergraduate pharmacy students in this environment was conducted and as such, it was crucial to explore how successful these placements have been from the student perspectives.

In particular, the objectives of this study were:

- To explore students' views as to whether the placement has helped their professional development

- To appreciate the potential of incorporating this type of non-traditional placement within pharmacy education

$\circ \quad$ To explore barriers and facilitators to providing this type of non-traditional placements

\section{Method}

This project was an evaluation of a particular practice with the aim to feedforward, improve and inform new practices; hence, it was an action research project. The action research process is based on a cycle taking the 
researcher around planning, acting, observing and reflection on a question (Baumfield et al, 2013).

\subsection{Data Collection Tool}

An evaluation form was designed based on findings from the first cycle of the authors' ongoing action research project on usefulness of targeted REPs in pharmacy education. Four broad areas were included, which allowed students to respond with free text: what the students aimed to get out of the placement, what went well, what didn't go so well and how the experience contributed to their learning. The evaluation form was handed to the students during their placement experience, so they could log their reflections. Students were asked to submit the form to the researchers at the end of the placement or at a later date to allow further reflection.

\subsection{Sampling Procedures}

\subsubsection{Sample Size and Method}

The sampling frame was all first year students who participated in the placement $(\mathrm{n}=110)$. Census sampling (Taub et al., 2014) was adopted and no exclusion criteria were applied. All forms submitted by students were considered for analysis.

\subsection{Data Analysis}

All references to individuals were removed during the transcribing process, to ensure anonymity. Free-text responses were analysed via coding and subsequent inductive thematic analysis.

\subsection{Ethical Approval}

Ethical approval for the study was granted by a University School Research Ethics Committee.

\section{Results}

Coding and subsequent inductive thematic analysis of the free-text responses revealed a number of key themes.

Table 2. Themes and Sub-Themes from Thematic Analysis of Students' Evaluation Forms

\begin{tabular}{ll}
\hline Theme & Sub-Theme \\
\hline $\begin{array}{l}\text { 1. Professional development of the } \\
\text { student }\end{array}$ & $\begin{array}{l}\text { Communication Skills } \\
\text { Personal confidence } \\
\text { Engaging with members of the public } \\
\text { Professional development more broadly }\end{array}$ \\
$\begin{array}{ll}\text { 2. Interacting with members of the public } \\
\text { - positive experiences and barriers }\end{array}$ & $\begin{array}{l}\text { Willingness of participant } \\
\text { Barriers to discussion }\end{array}$ \\
3. Patient Perspective / Experience &
\end{tabular}

Table 2 presents a summary of the main themes and their associated sub-themes. A description of each of the themes along with illustrative quotes will be provided.

\subsection{The Professional Development of the Student}

A significant number of students commented on their desire to improve their transferable professional skills during the placement, this included their communication skills, personal confidence and their ability to engage in an interaction with a member of the public. Most participants commented that these particular skills had improved as a result of the experience.

\subsubsection{Communication Skills}

The most common theme that emerged from the data was related to the students' communication skills. This was noted both as a desire to improve before the placement and that it had been improved as a result of the experience. Many students simply stated that they wished to:

"Improve communication skills"

The specific detail of how this skill would improve future interactions varied between individuals. Some participants commented that it would assist them with future assessments within the MPharm, such as in their "clinical skills assessment'; in contrast, others focused more on their interactions with patients whilst in a 'real' pharmacy. The 
experiences of the students also related more specifically to the REP with the mother and toddler group. Some students wished to tailor their communication skills to a particular group of patients and felt that the experience supported them in doing so:

'This experience has improved my skill set by allowing me to tailor my communication skills to different age groups"

"To improve my ability to talk to the public/patients in a style that was suitable - e.g. talk slower and clearer for some people"

"This experience has helped my professional development as it has reiterated to me how you have to change your choice of wording, volume and tone of voice and body language whilst speaking to people from different generations"

\subsubsection{Personal Confidence}

Many students commented that the experience gained through the REP impacted on their professional development through improving their confidence:

"It supported my professional development by improving confidence"

The rationale for wanting to improve confidence varied between individuals. Reasons included a desire to reduce anxiety around members of the public whilst others wished to improve their knowledge of the services that pharmacy can provide.

\subsubsection{Engaging with Members of the Public}

Many students commented on their skills in approaching individuals from the different age groups within the REPs:

"My confidence in approaching individuals to ask if I could discuss with them"

Participants provided conflicting views in terms of whether they needed to improve on this skill or not. Many felt that they were already competent in approaching members of the placement group whilst a larger number felt they needed to improve in terms of 'breaking the ice' and beginning their interaction. Some students felt very nervous in this situation; however, in contrast, many believed the experience assisted them in improving their ability to interact with members of the public:

"I was too nervous to approach someone on my own without the help of a supervisor"

"This has allowed me to gain confidence in approaching people and talking to them [public]"

\subsubsection{Professional Development Skills More Broadly}

Although general communication skills, personal confidence and engaging with members of the public were all raised frequently in the placement feedback the skills gained were not limited to these. There was a much broader scope of other skills students felt they wanted to improve or acquired from the experience. Example of these skills were related to empathy that students felt when talking with group participants and their questioning skills:

"Help me to empathise and understand patient experiences with children and medicine"

"The questions I asked usually got the required response and offering an open question lead to finding out more information"

\subsection{Interactions - Both Positive and Negative}

Many students commented on the successful nature of their interactions and the majority had positive comments of their experiences. In contrast, some students had faced challenges whilst undertaking their interactions with group participants.

\subsubsection{Ability to Speak to a Variety of Individuals}

The most common positive note regarding the interactions was the opportunity to engage with a variety of individuals. As a result of this, many students felt that they were able to gain a greater understanding of different patient experiences and therefore they were able to obtain knowledge of different health conditions:

"I was able to talk to a number of different people, each with different health conditions"

"(It) helped me develop an understanding of the variety of people we might come across"

In contrast, some students did not have such a positive experience and failed to engage with as many people as they had initially hoped to. A number of reasons were given for this, the first being that the mother and toddler group was 
quiet and therefore there were fewer individuals to approach. A second reason was that parents had already been approached by a number of students in previous visits and therefore were reluctant to participate in further discussion:

"The placement was quiet and so the number of people that were available to speak with was limited"

"Some parents had been approached in the past and didn't really want to speak again"

\subsubsection{Willingess of Participant to Engage}

A positive comment noted by a large number of students concerned participant willingness to speak. Students found individuals to be very easy to talk to, friendly, 'open' in answering their questions and freely shared their personal experiences:

"Many people were willing to talk and they gave a very good in-depth insight to their experiences"

\subsubsection{Barriers to an Open Discussion}

Although interactions were generally perceived to be successful by the students, a number of barriers to this were identified. The most commonly noted barriers were that members of the mother and toddler groups were often busy or distracted due to the presence of their children and were therefore reluctant to talk:

"A lot of the mothers were busy with their kids so didn't have much time to answer my questions"

"Some were reluctant to talk. Distracted by keeping an eye on their children"

In addition to this some group participants were not willing to talk to students in general. Some students found this to be a challenging situation:

"Some parents didn't want to talk which made it difficult"

\subsection{Patient Perspective/Experience}

The vast majority of students stated that they hoped to increase their understanding of the patient perspective. This included understanding patients' use of pharmacy and / or pharmacists, medication, healthcare services in general and the day to day issues individuals face regarding their health and medication (including compliance):

"(Hope to achieve/improve) understanding the parents/child minders perspective and opinions of pharmacists and other healthcare professionals"

"Gain an insight on how parents and their children cope with medication and illnesses"

"I got the opportunity to speak to a selection of different people about how easy it is for them to remember to take their medication"

"(The placement) allowed me to see how healthcare professionals communicate effectively. Also helped me to gain insight into a patient's perspective of the healthcare service"

In most cases students were able to successfully achieve their goal and improved their understanding of the issues facing group participants on a daily basis and within the context of pharmacy:

"I was able to talk to multiple people and find out about their experiences with Pharmacists"

This enabled students to develop a better understanding of the patient perspective thus understanding the role of the pharmacist and what is expected of them:

"It will help me see how the patients see pharmacists and what they expect from them"

"It increases my understanding of how the public sees pharmacists and what they want from a pharmacy"

Students commented more specifically on the needs of a parent and their child as this was identified as an area of weaknesss by students. Interactions with multiple groups of parents allowed them to have a broader understanding of issues facing parents and their children and the challenges this brings in relation to pharmacy:

"It has increased my understanding of being a parent and the challenges parents face"

"This experience has allowed me to increase my perception on the wide variety of needs of children"

"Gain perspective of what it is like to give medication to children" 


\section{Discussion}

\subsection{Overall}

This study has confirmed the benefit of focused REPs in novel settings for pharmacy undergraduate students. Careful consideration to planning of supervision and learning outcomes led to successful learning experiences. No supervision issues were identified as challenging from the students' perspective; this is unlike previously published evaluations (James and Prigg, 2004; Hook and Kenny, 2007; Thew et al, 2008) where students reported differences in expectations of supervisor. The learning outcomes were met, evidencing that structure and organization of this placement was appropriate for the chosen year of the students' degree. In line with the principles of a spiral curriculum (Bruner, 1960) completion of this placement will enable students to participate in more complex practice experiencens in future years.

In 2013, Elvey and colleagues explored the changing role of the pharmacist and the many areas that they are now practicing in (Elvey et al, 2013). With more emphasis on providing advice to service users and expansion into other areas of healthcare, such as general practice (GP) surgeries (Royal Pharmaceutical Socierty, 2012), the role is likely to continue to develop. In order to support new pharmacists with this ever increasing diversity it has been proposed, a five year integrated pharmacy degree which focuses on increased practical experience would have many advantages in adequately preparing students for practice. This would be in contrast to the current four year degree plus one year pre-registration (Smith and Darracott, 2011). An alternative approach, taken by other health care professions, to prepare students for diversity with their field, is the use of role-emerging placements (Whiteford and Wright St-Clair, 2002).

\subsection{Comparison with Literature}

\subsubsection{Development of Professional Identity}

A lack of professional identity was highlighted as a major issue for practising pharmacists as a result of recent changes (Elvey et al, 2013). Several studies, including those conducting full reviews in this area (Clouston and Whitcomber, 2008; Cooper and Raine, 2009; Clarke et al, 2014) highlightted that a key advantage of REPs was to provide the healthcare professional with a clearer understanding of their identity in practice and the ability to use their professional judgement. One of the seven principles set out by the GPhC for pharmacists to abide by is "Take responsibilities for your working practice" (GPhC, 2011). As research has shown (Clarke et al, 2015), REPs have given students autonomous skills which are crucial in developing into a pharmacy professional.

The majority of students in this particular study highlighted that the REP allowed them to develop professionally through a variety of ways. It also allowed them to have a greater awareness of the issues faced by patients and their perception of the pharmacist, all key issues to support the student in their understanding of their future role.

\subsubsection{Improving Inter-Professional Relationships}

There is increased emphasis on pharmacists using their skills in a range of areas and within multi-disciplinary teams (Smith and Darracott, 2011, Preslaski et al, 2013). Although this placement did not allow interaction with other HCPs it did provide patients to discuss their experiences with different members of the healthcare team. Through this students gained a valuable insight into their perspective of the healthcare service more broadly, not just the role of the pharmacist. This was deemed to be an advantage of the placement by students and provided a more holistic understanding of the NHS and patient engagement with it.

\subsubsection{Developing Confidence}

Perhaps the biggest advantage of the REPs in this study is that students, from an early stage of their studies gained confidence in engaging with members of public. This is particularly important as it has been highlighted in the literature by Moffitt and Davidson, that approximately $82 \%$ of students "would struggle" in their role as pre-registration pharmacist based on their current experience. Over the last decade, there have been many studies that acknowledge the importance of REPs in OT and the direct impact it has had on adequately preparing students for a practice that has "become more complex and diverse" (Overton et al, 2009; Dancza et al, 2013).

\subsubsection{Duration}

Currently there is limited literature around the use of REPs in pharmacy. One study conducted in Canada highlighted the positive aspects of REPs within the profession (Kassam 2013). However, it must be noted that this particular study focused on a placement which was significantly longer, six weeks in duration. As such, the results cannot be directly compared to this current study. In addition, the Canadian study did not focus on the student persception. A study published in the UK (Gwyn et al, 2015) suggested that there is even value in short experiences, such as that in 
this current study. The sample size of Gwyn and colleagues (2015) study does, however, provide limitations to the significance of the results. Only two students participated in placement in contrast to this study which evaluated the perceptions of 110 students and showed that despite the short duration professional development was achieved and the students succeeded in interacting with a range of memebrs of the public, gaining an insight into patient perspective.The value of has been more research into REPs role in occupational therapy with many short term advantages seen such as enhanced learning and increasing the diversity of placements available to the students (Fieldhouse and Fedden, 2009).

\subsection{Action Research - Completing the Cycle}

A study conducted by Overton et al (2009) in Australia reviewed how REPs were currently delivered. It was recommended that, for students to get the best out of the experience, they needed to be adequately prepared for the placement through effective communication, briefing and pre-placement interviews. Although conducted in Australia, this was also identified as an issue in the UK, with many students feeling more preparation was required prior to their placement (Boniface et al, 2012). The placements evaluated in this study all followed a pre-placement workshop where an attempt was made to prepare students. Results from the evaluation of students' perceptions in this placement were used to complete this action research cycle; all pre-placement material was subsequently reviewed based on the areas where students highlighted lack of preparedness or challenges identified during their placements. Newly developed material, to be incorporated in the next cohort of students attending REPs, included support materials, videos and leaflets for both students and service users.

The area that challenged the students most, as reflected from the results, was "breaking the ice". A tailored activity was developed, where discussion focused on examples of techniques around starting conversation and intergrating with groups of people already discussing without feeling you are interfering. This areas of development was supported additionally by the creation of teaching videos so students could visualize potential challenging situations before undertaking their placement. Also, leaflets were created, to be used as a flexible tool upon which to structure discussions. They could therefore be presented to parents/carers as a starting point of conversation.

Additional topics included students' concerns regarding parents or carers who were quiet or not willing to talk. Newly developed material in the pre-placement workshop will aim to reassure students that it is acceptable if someone doesn't want to talk and provided them with appropriate techniques toclose conversations and to move on to another without appearing rude or disheartened. There will now be further discussion and techniques and practice to further extend quiet conversations to include more open questions.

\subsection{Strength, Limitations and Future Work}

A common theme for studies evaluating REPs is the low sample numbers (Thew et al, 2008; Whiteford and Wright-St Claire, 2002; Gwyn et al, 2015) which greatly decreases validity and it must be established whether this approach would work for a larger student sample. This study explored perceptions of 110 participants comprising a full cohort of entry level undergraduate pharmacy students, which provides confidence on generalizability of results.

In this study we did not seek to explore any parents' or placement facilities hosts' views on sustainability of these placements. However, anecdotal feedback from service users attending the mother and toddler groups (informal email to academic placement lead) was overwhelmingly positive. Also, all organisors of groups informally confirmed that they would be willing to continue the collaboration with the School for next academic year. The cohort of parents/carers attending the groups is renewed at regular intervals, so they did not expect any issues around overburdening them when asking them to participate in discussions with students.

The evaluation described in this study did not include any qualitative methodology, such as interviews or focus groups to explore identified issues further. In line with the realistic approach in action research that there is a continuum of enquiry between different approaches (Baumfield et al, 2013), the researchers started with evaluation of feedback forms. This, in turn, will inform a schedule for qualitative work, which will look beyond the individual's behaviour to how that is related in a social context.

The perceptions of a full cohort of entry level undergraduate pharmacy students were explored at one point in time. Whilst results informed student preparation within a pre-placement workshop environment for the following cohort of students, it would be beneficial to conduct a longitudinal study to research how such a placement experience has influenced practice of pharmacy graduates. 


\section{Conclusion}

This paper describes the second phase of an ongoing action research project focusing on integration of REPs in innovative environments to the MPharm curriculum in the UK. The pilot scheme exposing students to elderly patients was well received by all stakeholders involved, and led to REPs being rolled over to the following academic year. The cycle discussed in this study related to designing, implementing and evaluating another novel placement related to exposing students to challenges surrounding pharmaceutical care of young children. Results increase confidence in the value of integrating short-duration REPs in other pharmacy undergraduate curricula; careful consideration of structure, placement educators' consistency in supervisory approaches, learning outcomes and preparation of the students is pivotal to the success of such schemes.

\section{References}

Abbas, M., Burrow, J., \& Rudokas, M. (2013). An evaluation of the placement scheme on the MPharm degree. Diffusion: the UCLanJournal of Undergraduate Research, 6(2).

Baumfield, V., Hall, E., \& Wall, K. (2013). Action Research In Education (2nd ed.). London, England: SAGE Publications Ltd.

Boniface, G., Seymour, A., Polglase, T., Lawrie C., \& Clarke, M. (2012). Exploring the nature of peer and academic supervision on a role-emerging placement. British Journal of Occupation Therapy, 75(4), 196-201. http://dx.doi.org/10.4276/030802212X13336366278211

Bruner, J. (1960). The process of education. Cambridge, MA: The President and Fellows of Harvard College.

Clarke, C., Martin, M., De Visser, R., \& Sadlo, G. (2014). Role-emerging placements: a useful model for occupational therapy practice education? A review of the literature. $P H B L, 2(2), 1-13$. http://dx.doi.org/10.11120/pblh.2014.00020

Clarke, C., Martin, M., De Visser, R., \& Sadlo, G. (2015). Sustaining professional identity in practice following role-emerging placements: Opportunities and challenges for occupational therapists. British Journal of Occupational Therapy, 78(1), 42-50. http://dx.doi.org/10.1177/0308022614561238

Clouston, T.J., \& Whitcombe, S.W. (2008). The professionalisation of occupational therapy: A continuing challenge British Journal of Occupational Therapy, 71(8), 314-320. http://dx.doi.org/10.1177/030802260807100802

Cohn, E. S., \& Crist, P. (1995). Back to the future: New approaches to fieldwork education. American Journal of Occupational Therapy, 49, 103-6. http://dx.doi.org/10.5014/ajot.49.2.103

College of Occupational Therapists. (2006). Developing the occupational therapy profession: providing new work-based learning opportunities for students. College of Occupational Therapists Guidance, 4. London: COT.

Cooper, R., \& Raine, R. (2009). Role-emerging placements are an essential risk for the development of the occupational therapy profession: the debate. British Journal of Occupational Therapy, 72(9), 416-18. http://dx.doi.org/10.1177/030802260907200910

Dancza, K., Warren, A., Copley, J., Rodger, S., Moran, M., Mckay, E., \& Taylor, A. (2013). Learning experiences on role-emerging placements: An exploration from the students' perspective. Australian Occupational Therapy Journal, 60, 427-35. http://dx.doi.org/10.1111/1440-1630.12079

Durham University. (2015). Placements. Retrieved 25 $5^{\text {th }}$ August $2015 \quad$ from https://www.dur.ac.uk/school.health/ug.pharmacy/undergraduate/placements

Elvey, R., Hassell, K., \& Hall, J. (2013). Who do you think you are? Pharmacists' perceptions of their professional identity. International Journal of Pharmacy Practice, 21, 322-32. http://dx.doi.org/10.1111/ijpp.12019

Fieldhouse, J., \& Fedden, T. (2009). Exploring the learning process on a role-emerging practice placement: a qualitative study. British Journal of Occupation Therapy, 72(7), 302-7. http://dx.doi.org/10.1177/030802260907200705

General Pharmaceutical Council. (2010). Health Care and Associated Professions. Retrieved $4^{\text {th }}$ August 2015 from https://www.pharmacyregulation.org/sites/default/files/General\%20Pharmaceutical\%20Council\%20\%28Constit ution\%29\%20Order\%202010.pdf

General Pharmaceutical Council. (2011a). Future Pharmacists: Standards of initial education and training for $\begin{array}{lllll}\text { pharmacists. } & \text { Retrieved } & 5^{\text {th }} & \text { August } & 2015\end{array}$ 
https://www.pharmacyregulation.org/sites/default/files/GPhC_Future_Pharmacists.pdf

General Pharmaceutical Council. (2011b). Pre-registration Manual. Retrieved $5^{\text {th }}$ August 2015 from http://www.pharmacyregulation.org/sites/default/files/2011-12\%20Pre-registration\%20Manual\%20o.pdf

General Pharmaceutical Council. (2015a). Pharmacist education. Retrieved $5^{\text {th }}$ August 201 from https://www.pharmacyregulation.org/education/pharmacist-education

General Pharmaceutical Council. (2015b). About us. Retrieved $5^{\text {th }}$ August 2015 from https://www.pharmacyregulation.org/about-us

Gwyn, H., Herring, O., \& Mantzourani E. (2015). Exploring sexual health in a role-emerging placement with young people. Pharmacy Education, 15(1), 227.

Health and care professions council. (2009). Standards of education and training. Retrieved $5^{\text {th }}$ August 2015 from http://www.hcpc-uk.org/assets/documents/1000295EStandardsofeducationandtraining-fromSeptember2009.pdf

Hook, A., \& Kenny, C. (2007). Evaluating role emerging placements. OT news, 15(7), 25.

Huddleston, R. (1999). Clinical placements for the professions allied to medicine, part 2: Placement shortages? Two models that can solve the problem. British Journal of Occupational Therapy, 62(7), 295-98. http://dx.doi.org/10.1177/030802269906200704

James, C., \& Prigg, A. (2004). A self-directed fieldwork program to provide alternative occupational health placements for undergraduate occupational therapy students. Australian Occupational Therapy Journal, 51, 60-68. http://dx.doi.org/10.1111/j.1440-1630.2004.00422.x

Kassam, R., Kwong, M., \& Collins, J. B. (2013). A demonstration study comparing "role-emergent" versus "role-established" pharmacy clinical placement experiences in long-term care facilities. BMC Medical Education, 13, 104. http://dx.doi.org/10.1186/1472-6920-13-104

Mantzourani, E., \& Deslandes, R.E. (2013). Pharmacy undergraduates' views on discussion as a tool to enhance reflections on observational placements $17^{\text {th }}$ International Reflective Practice Conference Swansea.

Mantzourani, E., \& Hughes, L. (2015). Working outside the dispensary: Role-emerging placements enable pharmacy students in all years to work with members of the public and learn about their needs The Pharmaceutical Journal, 295, 7882. http://dx.doi.org/10.1211/PJ.2015.20069335

Moffitt, K., \& Davison K. (2015). Do Community Pharmacy Placements Support the new Integrated Approach to Pharmacy Education?: Stakeholder and Student Perspectives. Retrieved $27^{\text {th }}$ July 2015 from http://www.npa.co.uk/wp-content/uploads/2015/09/HEF-Pharmacy-Placements.pdf

National Health Service Wales. (2014). Our plan for a primary care service for Wales up to March 2018. Retrieved $17^{\text {th }} \quad$ September 2015 from http://www.wales.nhs.uk/sitesplus/documents/986/Our\%20Plan\%20for\%20Primary\%20Care\%20in\%20Wales\% 20up\%20to\%20March\%202018.pdf

Noble, C., O'Brien, M., Coombes, I., Shaw, P., Nissen, L., \& Clavarino, A. (2014). Becoming a pharmacist: Students' perceptions of their curricular experience and professional identity formation. Currents in Pharmacy Teaching and Learning, 6, 327-39. http://dx.doi.org/10.1016/j.cpt1.2014.02.010

Overton, A., Clark, M., \& Thomas, Y. (2009). A review of non-traditional occupational therapy practice placement education: a focus on role-emerging and project placements. British Journal of Occupational Therapy, 72(7), 294-301. http://dx.doi.org/10.1177/030802260907200704

Preslaski, C. R., Lat, I., MacLaren, R., \& Poston, J. (2013). Pharmacist Contributions as Members of the Multidisciplinary ICU Team. Chest, 144(5), 1687-95. http://dx.doi.org/10.1378/chest.12-1615

Rodger, S., Thomas, Y., Holley, S., Springfield, E., Edwards, E., Broadbridge, J....Hawkins, R. (2009). Increasing the occupational therapy mental health workforce through innovative practice education: A pilot project. Australian Occupational Therapy Journal, 56, 409-417. http://dx.doi.org/10.1111/j.1440-1630.2009.00806.x

Royal Pharmaceutical Society. (2012). The Changing Face of Pharmacy. Retrieved $5^{\text {th }}$ August 2015 from https://www.rpharms.com/public-affairs-pdfs/rps-changing-face-of-pharmacy-booklet.pdf

Smith, A., \& Darracott, R. (2011). Review of pharmacist undergraduate education and pre-registration training and proposals for reform. Report to Medical Education England Board. Retrieved 4 ${ }^{\text {th }}$ August 2015 from http://hee.nhs.uk/healtheducationengland/files/2012/10/Pharmacist-pre-registration-training-proposals-for-refor 
m.pdf

Taub, N., Douiri, A., \& Walker, D. (2014). An introduction to health services research. Walker, D. (ed.), SAGE publication ltd, London (UK).

Thew, M., Hargreaves, A., \& Cronin-Davis, J. (2008). An evaluation of a role-emerging practice placement model for a full cohort of occupational therapy students. British Journal of Occupational Therapy, 71(8), 348-53. http://dx.doi.org/10.1177/030802260807100809

University College London School of Pharmacy. (2015). Career Development. Retrieved $25^{\text {th }}$ August 2015 from https://www.ucl.ac.uk/pharmacy/current-students/career-dev

Whiteford, G., \& Wright St-Clair, V. (2002). Being Prepared for Diversity in Practice: Occupational Therapy Students' Perceptions of Valuable Inter-cultural Learning Experiences. British Journal of Occupational Therapy, 65(3), 129-137. http://dx.doi.org/10.1177/030802260206500305

Wood, A. (2005). Student Practice Contexts: Changing Face, Changing Place. British Journal of Occupational Therapy, 68(8), 375-378. http://dx.doi.org/10.1177/030802260506800806 